\title{
افتتامية العدد
}

يطيب لكلية الدراسات الاقتصادية والعلوم السياسية بجامعة الإسكندرية أن تقدم للباحثين والطلاب والقراء العرب العدد التاسع من مجلتها العلمية (يناير 2020). ويضم العدد خمس دراسات هامة ومتنوعة؛ حيث تعالج الدراسة الأولى ظاهرة الانتشار الديمقراطي وما يتعلق بها من ظواهر حال التحول الديمقراطي والانتقال الديمقراطي؛ وكلها ظواهر بالغة الأهمية على الصعيدين العملي والفكري لاسيما خلال الفترة الراهنة والتي ترتد بداياتها إلى تقكك الاتحاد السوفييتي عام 1991 ومن ثم تبلور النظام العالمي الجديد وهيمنة الليبرالية فكراً وتطبيقاً بانحسار الماركسية الكبير، والدراسة للدكتور وليد قاسم وهي بعنوان الانتشار الديمقراطي: دراسة في الآليات والمسارات والمحددات. أما الدراسة الثانية فهي لاثثين من الأكاديميين الكويتيين هما: الاكتور/ محمد عمر باطويح والدكتور / فيصل حمد المناور، وتتعلق الدراسة بعملية التخطيط التتموي في دولة الكويت ارتباطاً برؤية 2035،

وهي دراسة بعنوان: التخطيط التتموي في دولة الكويت: التحديات وسبل مواجهتها. وينصب اهتمام الدراسة الثالثة على أحد الموضوعات الهامة المتعلقة بحقل التنظير في العلاقات الدولية. حيث تقدم تحليلاً معقماً ومستفيضاً لموقف مختلف نظريات السياسة الدولية من ظاهرة بحث القوى العظمى الدائم عن الهيمنة. والدراسة بعنوان: مفهوم الهيمنة في نظريات العلاقات الدولية، وهي من إعداد الدكتورة/ مروة خليل.

أما الدراسة الرابعة؛ فتعرض بالتحليل لموضوع هام يتعلق بمدى فعالية منظمة الأمم المتحدة في إدارة الصراع الدولي ولاسيما الأزمات الدولية، وتتصب تحديداً حول دور المنظمة الدولية في إدارة الأزمة العراقية الثانية المترتبة على التدخل الأمريكي في العراق عام 2003. والدراسة مقدمة من باحث الدكتوراه/ علي يونس النعيمي، وهي معنونة: دور الأمم المتحدة في إدارة أزمة حرب الخليج الثالثة (2003): "دراسة تقويمية". ثم تأتي الدراسة الخامسة والأخيرة في هذا العدد لباحث الماجستير/ عمار عدنان شمران وهي دراسة هامة تتعلق بتقويم منظومة العمل العربي المشترك ممثلة في جامعة الدول العربية ومدى فعاليتها في إدارة الأزمات والصراعات العربية، وعنوان الدراسة: دور جامعة الدول العربية في إدارة الأزمة السورية في ضوء ثورات الربيع العربي (2011-2018).

وهكذا تتظظم بحول الله أعداد المجلة العلمية لكلية الدراسات الاقتصادية والعلوم السياسية بجامعة الإسكندرية كمجلة نصف سنوية تسعى إلى الريادة بين نظيراتها المتخصصة في مجالات الاقتصاد والعلوم السياسية على الصعيدين الوطني والإقليمي؛ وتقديم إضافة يعتد بها إلى المكتبة العربية في تخصصيها بالغي الأهمية. وكعادتنا نتطلع دوماً إلى تقديم المزيد من الدراسات الرصينة المحكمة في ثنايا أعداد قادمة، والله من رئيس التحرير وراء القصد.

أ.د. أحمد محمد وهبان 